\title{
PROJECT PLANNING AND IMPLEMENTATION IN RWANDA NATIONAL UNION OF DEAF PROJECT KICUKIRO DISTRICT
}

\author{
Kadiho Alpha ${ }^{1}$, Nyabera Onsoti ${ }^{2}$, Dr. Alice Kituyi, $\mathbf{P h D}^{\mathbf{3}}$. \\ ${ }^{* 1,2}$ School of Business and Economics, Mount Kenya University, Rwanda $;{ }^{3}$ School of Postgraduate Studies, Mount \\ Kenya University, Rwanda. \\ ${ }^{1}$ Email:alphakadiho77@gmail.com $;^{2}$ sonsoti@mku.ac.ke; ${ }^{3}$ awafula@mkurwanda.onmicrosoft.com
}

*Corresponding Author: -

Email: alphakadiho77@gmail.com

\begin{abstract}
: -
A number of donors funded project fail during implementation stage due to poor planning. This study objective was to assess the impact of project planning on implementation in Rwanda National Union of Deaf (RNUD) Project. Specific objectives of the study included: to determine ways in which project planning impacts on successful implementation of Rwanda National Union of Deaf (RNUD) Project in Kicukiro District; to establish how project implementation processes are accomplished in the Rwanda National Union of Deaf (RNUD) Project in Kicukiro District; and to determine the impact of project planning on project implementation of Rwanda National Union of Deaf (RNUD) Project in Kicukiro District. The researcher used descriptive research design for data analysis. The researcher used a simple random sampling to select 112 respondents including 16 respondents who included project donors and employees, who were given questionnaires to provide quantitative data. Pearson correlation and multiple linear regression analysis models with help of SPSS version 21.0 were used to analyse the collected data from the field. The results revealed a positive and significant relationship between project planning and implementation of Rwanda National Union of Deaf (RNUD) Project in Kicukiro District, Rwanda. For instance, the positive and significant relationship between project scope planning and team development $(r=.821$ and $p=.000)$, between project scope planning and task assignment $(r=.787$ and $p=.000)$, between project scope planning and plan execution $(r=.848$ and $p=.000)$ between project resource planning and team development $(r=.834$ and $p=.000)$ between project resource planning and task assignment $(r=.772$ and $p=.000)$ between project resource planning and plan execution $(r=.858$ and $p=.000)$ For the findings, the study recommend project employees should be equipped with more planning skills to enhance the process of project planning by including the project beneficiaries, The researcher would also like to recommend to project beneficiaries to be part and parcel of project planning and implementation process of RNUD Project to enhance its performance and ensure full participation of stakeholder to enhance productive implementation process of project and beneficiary satisfaction.
\end{abstract}

Keywords: Project planning, Project implementation, Project scope planning, Project resource planning, Stakeholder participation, Rwanda

\section{(c) $\circledast(1)$}




\section{I.INTRODUCTION}

\subsection{Background of the Study}

Project planning as defined by PMBOK (PMI, 2013) refers to the formulation of a project guide that will provide direction on the project implementation and project control. The main role for project planning is to provide an overall guide towards achieving the success of the project. According to PMI (2013) states that project planning is phase two of the project life cycle following initiation phase and it focuses on developing a roadmap in which all the people involved in project development, execution, monitoring and evaluation can follow. During this stage, the project scope, budget and time frame are clearly identified and specified. It is therefore crucial step in ensuring project implementation and success.

In the selection of a project, care must be taken in order to ensure its performance. But once a project is selected, its success is much pegged on the planning that has been done. This requires a strong synchronization between objectivity and core objectives of the project to exclude any potential influence from individuals. In addition, availability of core resources needed for the project success should be properly indicted. These resources include people with corresponding skills, finance, time and materials. The planning phase is a stage where all these resources should be outlined for smooth take off and successful completion of project. As noted by Melton (2011), project planning is a stage that can determine the future performance of project. It should be therefore designed to detail and to completion. At the same time, it should effectively be communicated to all parties involved in the project.

However, even the best laid plans can fail if the implementation is not affected efficiently. Project planning phase is followed by project implementation phase. According to Dionne (2018), project planning can influence the performance of project implementation stage. Project planning is globally important to the extent that any individual willing to participate in any project being at community or professional level is required to hold skills allowing him/her to engage teamwork activities. Government institutions face needs and demands from the public to deliver on the projects they initiate.

Various countries on realization of the importance of project planning on the whole project life cycle have created centres within the governments and government institutions to ensure that the projects do perform. For instance, according to Gasik (2016) the UK government has put in place the Major Projects Authority (MPA) under the cabinet and mandated to ensure improved delivery of public projects. Similarly, in the US, the office of management and budget reports directly to the US president play such functions. These are attempts by different governments to ensure project success in planning and implementation as well as in the delivery of the intended results to the public.

Projects are generally understood as activities with a special status that distinguished them for the usual activities exercised in projects (PMI, 2013) and they may ascribe certain tensions to the partakers which includes for example the project being a short-term and competing for resources with the existing ongoing activities.

In Rwanda, various projects close due to non-commitment or deviation from the set objectives leading to fraudulent use of resources intended for community development. Some project delay incompletion filing to meet timeframe that is set in the project planning. Other projects escalate in cost spending more than budgeted. These challenges and others are mainly caused by the factors but lack project planning that is at the forefront. Project management is careful planned and organized effort and accomplish a particular (and usually) timely effort, for example developing a building or making use of a new computer system (Remon \& Sherif, 2013).

The researcher has investigated the effect of project planning on implementation of donor funded project with a case of Rwanda National Union of Deaf (RNUD) Project in Kicukiro District, Rwanda.

\subsection{Problem Statement}

For projects to customize themselves to globalization, changing environment and respond to their desire of being competitive, they need to engage in rethinking their processes. This is mainly achieved through thorough and extensive project designing and planning to ensure all requirements and scope specifications are laid out mainly through empowering, entrusting and involving the stakeholder in the planning phase. This can enhance the work that the managers are doing especially in regard to developing project teams (MININFRA, 2017).

Projects can be viewed as successful projects when they are performed within a specific time period, within an assigned budget and are able to maintain high quality (Owolabi et al., 2014). Delay in the completion of projects has become a big challenge globally and leads to an increase in the cost invested in the project, which is divided in phrases of prolonged time, employee productivity, job interruption, loss of revenue and complete project abandonment. The length in completing the projects has a detrimental impact on customers, contractors as well as the intended beneficiaries. These delays are associated with poor planning and implementation problems. Rwanda National Union for the Deaf (RNUD) collaborated with other stakeholders and donors to enhance capacity building among the deaf as the primary beneficiaries of the project. A report by RNUD (2017) stated that majority of their challenges were concerned with the involvement of beneficiaries in planning and implementation process when beneficiaries of the project are deaf which and when these two projects need sometimes planning skills. However, through joint planning and implementation with consultation and involvement of the deaf through sign language, they have managed to enhance effective implementation of project that results in performance and project success. The problem is therefore to address the issues of effective planning in order to ensure increased capacity to deliver services and implementation of this project. It is therefore important that this study is undertaken to understand the contribution of effective project planning to successful implementation of projects in Rwanda National Union of Deaf (RNUD) Project in Kicukiro District. 


\subsection{Objectives of the study}

The general objective of this research is to examine the impact of project planning on the successful implementation of the Rwanda National Union of Deaf (RNUD) project in Kicukiro District.

The specific objectives included:

(i) To determine ways in which project scope planning impacts on successful implementation of Rwanda National Union of Deaf (RNUD) Project in Kicukiro District.

(ii) To establish how project resource planning is accomplished in the Rwanda National Union of Deaf (RNUD) Project in Kicukiro District.

(iii) To determine the impact of stakeholder participation on project implementation of Rwanda National Union of Deaf (RNUD) Project in Kicukiro District.

\section{Literature Review \\ 2.1 Theoretical Literature \\ 2.1.1 Project Planning Concept}

Project planning as defined by PMBOK (PMI, 2013) refers to the formulation of a project guide that will provide direction on the project implementation and project control. The main role for project planning is to provide an overall guide towards achieving the success of the project. According to PMI (2013), project planning is a management function whose objective is to provide an overall guide to what the project manager and his team need to do to bring the project to completion. It is seen as a process that is oriented towards bringing desired output. Project planning therefore involves setting up guidelines and tasks to be undertaken in the project life cycle. Further, it is during the project planning process that teams are developed, individual skills identified and tasks allocations are done.

According to Barret (2018) project life cycle which refers to a sequence of different interconnected phases of project and passes through time of initiation to time of completion, is composed of four main stages. These phases include project initiation, project planning, project implementation and closure of the project. A standard project will pass through these key stages to bring it to completion. However, different management may adopt several stages and the sequence of the project cycle may end up having many phases depending on the nature and the needs of the project. This shows that though there can be standardized phases that a project can pass through; there is room for flexibility and adaptation that the project management team can decide to follow. According to Ajam (2015) therefore, project life cycle can be defined and modified to suit the particular needs and targets of the institution involved.

In fact, project planning implies putting more efforts in bringing together teams involved in the project, being more open to ideas, being ready for questions that may be asked and providing orientations. These questions will be asked from the beginning to the end of the project when stakeholders or beneficiaries celebrate the achievement of reaching the project's ultimate goal (Abraham, 2014).

In the standard project life cycle, however, it is noted by Pica (2015) that project planning is the second phase in project life cycle following the project initiation phase. It focuses on developing a roadmap in which all the people involved in project development, execution, monitoring and evaluation can follow. During this stage, the project scope, budget and time frame are clearly identified and specified. It is therefore a crucial step in ensuring that project implementation is achieved within the specification and there is an overall project success. The project planning phase provides the project and the team with the action plans, resource plan, budget plan and time plan to be undertaken throughout the project life as well as providing with task allocation plans (Martinelli \& Milosevic, 2016).

\subsubsection{Project Scope Planning}

Project planning phase is crucial in setting up and facilitating the scope of the project. According to Fageha \& Aibinu (2013) project scope refers to defining the requirements, the boundaries, clients' specification and the overall project designing. It involves cutting out the specifications of the project in order to meet the particular needs of the client taking into considerations the constraints therein. Project scope definition is therefore a crucial step in the project planning stage. Project scope planning involves various steps in the development of the project. These include cumulative requirements, defining scope, increasing work breakdown structures, verifying and controlling scope.

In the project planning phase, project scope planning is the first step towards successful implementation of a project. According to Le Blanc, et al., (2020) scope planning involves developing a summary that provides the project team with all the needed information on how to proceed with the project. The project scope planning comes after the approval of the project in the initial phase of the project life cycle. It is a component feature of project planning and when effectively done can lead to high project performance. As discussed by Levitt (2013) effective project scope planning has a positive and significant effect on the overall project management processes.

Further, project scope planning involves the definition of the scope as needed to accomplish the project. In the definition of the scope, various documentations are made to ensure there is detailed description of the project scope. In this regard the client's specific details are laid down in line with the inputs from architecture experts. It is with good scope management that project implements and success can be assured for all the concerned stakeholders (Abraham, 2014). For instance, RNUD Project carried out in different Districts in Rwanda can achieve their objective through scope definitions and effective scope planning management.

According to Martinelli and Milosevic (2016), scope planning also involves work breakdown structure (WBS) which refers to the decomposition of the project into various works to be executed. In this case, the entire project is broken out in to hierarchical constituent components. The main objective here is to ensure maximum attention to each and every 
component is achieved. It allows for more accurate project management and better resource allocation. As noted by Verzuh (2016), work breakdown structure assist project managers in focusing on each of the components constituted in the project enabling them to specifically add necessary details progressively as need be. By performing WBS to a project, the project manager improves the flow of information throughout the project. This is because real time feedback can be extracted from smaller components as opposed to extracting from the wider project.

In conclusion, project scope planning also involves project designing. According to Akdeniz (2015) project design involves the very early phase of project planning where the key elements and features are outlined. In this time the major deliverables for the project are also planned. The management team should aim at developing one or more project designs that meets the customer specifications. According to PMI (2013), the developed project design need to be reviewed as early as possible before resources as committed. This design review ensures a thorough evaluation of the proposed design to make sure that it is meeting the specifications required by the customers. Hence it becomes a critical point to be integrated to the project management.

\subsubsection{Project Resource Planning}

As discussed by Coles and Barritt (2014) project resource planning involves providing a summary of all the resource required to complete a project. Such resources include materials, finances, and people, among others. Resource planning in project management is very crucial in the success of the project. In fact, the successful kick off any project is pegged on the resource planning of the project. As stated by Ganesh et al. (2016) a project cannot effectively be implemented without first availing the required resources. Therefore, the implementation of a given project would require specification and effective planning of the necessary resources. Resource planning for a project will involve specifying the resource according to the project design, checking the availability of the resources, identifying key suppliers and coordinating the acquired resources.

According to Zandhuis, Paul and Thomas (2017) once the initial plans of a project are laid down and the design has being put into place, resource planning has to be done to ensure resources are identified, are available, and can be sufficient to complete the project. In fact management of project involves resource management. The first step in resource planning is to plan for the resource requirements. This requires that the project manager estimates the required resources for each of the project life cycle and for each activity to be undertaken. A holistic approach to resource planning requires that the estimation be done on the resource estimation from the start to the completion of the project. However to achieve this, the project manager and his/her team should break down the entire project life into different phases of activities and determine the resource requirement for each of these. This in effect help to determine the totality of the resources needed to run the project (Huemann, 2016).

In addition, resource estimation involves resource specification. Based on the project design and client specification, a project manager in collaboration with other experts like engineers should be able to specify the quality of the resources required to deliver quality output (Pheng, 2018). Further, at this stage, the project resource planning should also identify key suppliers of such resource. Being able to identify suppliers can help in reducing cost of acquisition as well as avoiding future stock out. Further, having suppliers at hand can help the management to cover for unexpected resource needs in the course of project implementation.

According to Levitt (2013) resource planning should be in line with the different tasks that are to be performed in a project. For each task, the project management team should scrutinize the activities to be carried out, how and then be able to determine the resource requirement for the successful implementation of the task. Once the resources needed are acquired, the project management team should be wary about how to allocate such resources according to planned tasks. Therefore, resource planning goes further to involve resource coordination planning. This would ensure that a project implementation process is done more efficiently and smoothly. In resource allocation planning, the project manager decides which resource is to be assigned to what task. It also involves scheduling the available resources in the most efficient and economical way (Huemann, 2016).

\subsubsection{Stakeholder participation}

Stakeholder participation is the process of engaging the project stakeholders or all people that are affected or affect the project implementation (Usadolo \& Caldwel, 2016). This implies that stakeholder participation allows the stakeholders of the project to be involved in planning and implementation processes of the project to increase resource planning and execution of the project plan.

The literatures have shown that stakeholder participation improved the quality of local long-term management. Theoretically, the inclusion of specific stakeholders increases the quality of project management and project implementation because the determined stakeholders have relevant knowledge and skills regarding effective management and implementation of the project (Roovers \& van Buuren, 2016). They added that stakeholder participation promotes quality of planning by incorporating more information from different opinions and views of people and it enhances the acceptance of planning due to the fact that it takes into account more goals and views of people.

\subsection{Empirical Literature}

Zwikael \& Meredith (2019) conducted research investigating implications of project planning on the overall performance of project in commercial projects. Citing failure of many projects, the researchers carried out a factor analysis and correlation analysis to determine the relationship between project planning and success of projects in terms of their performance. The results of the factor analysis showed that there are various factors that contribute to the 
performance of projects. The most important were identified as nine while conformity to the requirements was the main and important factor. In addition, sound project planning was identified as a key factor. The correlation analysis revealed that the Pearson's coefficient is 0.23 between project planning and project performance.

On his part, Serrador (2013), carried out a desk top research investigating empirical literature on the impact of project planning on the success of the project. In this study, the concern was to establish the link between planning and project success as reported through various empirical evidences in literature. In analysing a total of 280 papers and books, the research was able to summarize the correlation between project planning and performance. According to the findings, there is consistence in the empirical results showing existence of correlation between planning and success. The average value for $\mathrm{R}^{2}$ obtained is 0.33 between project planning and efficiency and an average $\mathrm{R}^{2}$ of 0.34 between project planning and the overall project performance.

On the impact of project planning on the success of projects, Naeem, et al., (2018) carried empirical research with risk management and organizational culture as mediating variables. They used questionnaires to collect primary data using 100 project managers who were selected using convenient sampling technique. The results revealed that there is a positive and significant relationship between project planning and project success with a correlation of 0.553 . The research also used moderated regression analysis to test the hypothesis where the results showed the model to be significant with p-value less than $5 \%$.

Related research is by Igwe and Ude (2014) on project planning and implementation in Nigeria. This research aimed at exploring the link between project planning and implementation in line with international best practices. They carried out a documentary review of literature. The finding pointed out that there exist different literature emphasizing the link between project planning and implementation.

In Rwanda, Ong'aro and Asumptah (2017) carried out research on the determinant of successful implementation of Housing projects in Rwanda. A sample of 182 employees in the Roko construction company was selected and primary data gathered using structured questionnaires. Among the factors investigated, top management, communication channels and project planning were found to have positive and significant effect on the implementation of projects. Project planning was proven that there is a positive and significant correlation with project implementation with $r=$ 0.318 and a p value which is below 5\%. Similarly, Kanyago and Shukla (2017) conducted research on the role of project management skills on performance of construction projects in Rwanda. In their research, questionnaires were distributed to a sample of 33 respondents. The results revealed that project management skills influences project performance with $\mathrm{R}^{2}$ of 0.306 . In addition, project planning skills have a significant relation with project performance.

\subsection{Theoretical Framework \\ 2.3.1 Stakeholders' Theory}

Freeman (1984) is credited to have first fronted the stakeholder theory. According to him, stakeholders are groups or individuals who are affected by, or who affect the organization's activities. The stakeholder theory states that building strong stakeholders' relationship enhances strong and positive outcomes of a project. According to Rodriguez et al., (2002) project success can be achieved by strengthening stakeholder relationships emanating from trust, reputation and innovation which translate to better performance of the organization. Involving different stakeholders can lead to an effective project implementation and consequently project success. By involving the key stakeholder, a project manager is able to easily identify the client's needs as well as the resources needed.

The stakeholder theory posits that organization is a social building formed by ways of the interaction of various stakeholders. The organization is seen as the core of part of a community of stakeholders with system of exchange replacing services, information, influence and other resources. The theory is also applied to project management where the projects managers are encouraged to involve all the key stakeholders in order to enhance performance and as well as enhance sustainability of these projects.

\subsubsection{Resource Based Theory}

Resource based theory is also known as Resource Base View (RBV) and considers internal resources in an organization as key to superior project performance. It was introduced in the 1980s by Wernerfelt (1984) as an approach to achieving organizational competitive advantage. The theory stresses that the project success lies right within the available resource capabilities. In the organization running a project is endowed with the right resources, then there is high possibility it is going to be a success. This is because such a project will be able to attract all the needed resources to complete the project successfully.

The resource based theory is founded on the belief that whatever resources that a company has be they human resources, financial resources, assets and none financial resource, all of these are strengths and capabilities that a company can use to enhance its competitive advantage. The resources also play a bigger role in determining what type of strategic action the company can take as compared with the external resources which have a smaller influence. Since this internal resources offer opportunities for further strategic growth rather than decline, management should focus on them as internal strength factors (Peppard \& Ward, 2016). Therefore, the theory holds that effective resource management is key to any project success. Therefore, there is much need for project planning aimed at resource identification and acquisition. It is only through effective planning can managers be able to achieve success in the implementation of the project. 


\subsection{Conceptual Framework}

Source: Researcher (2020)

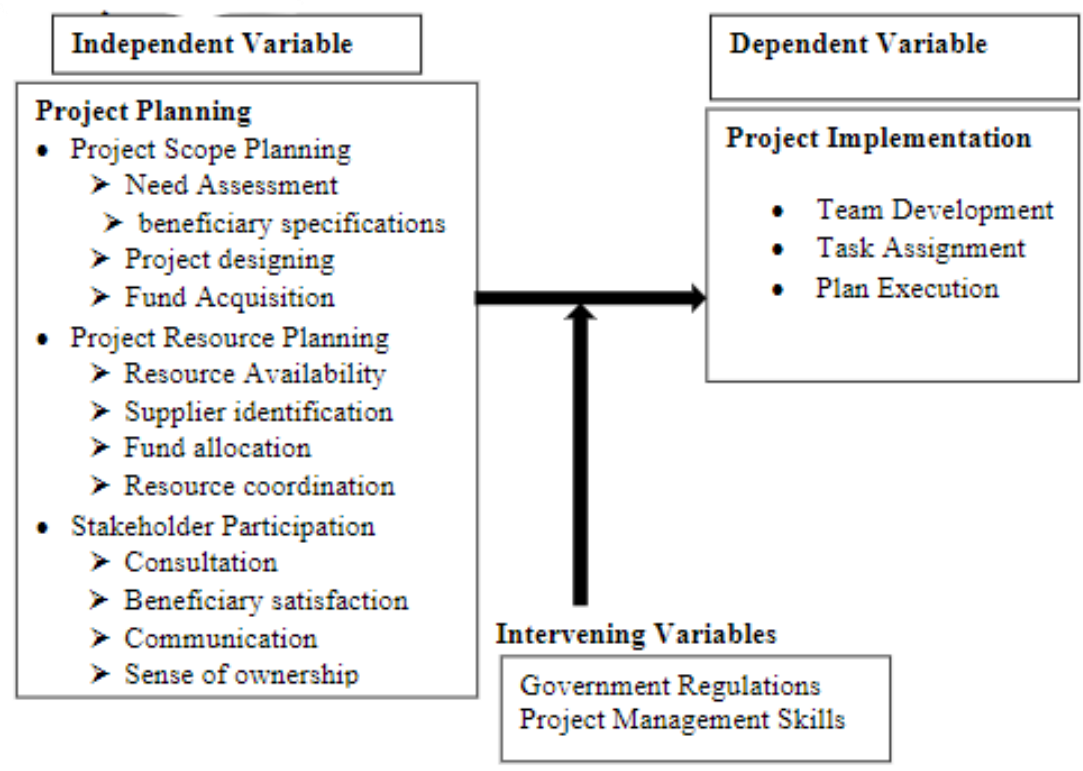

Figure 1: Conceptual Framework

The conceptual framework represented shows the relationship between the variables under this study. On one side is the independent variable which is project planning. The indicators under this variable include project scope planning, project resource planning and stakeholder participation. The project scope planning gives details on the specific requirements of the project, the client specification and the intended quality of the project. This entails a complete project design which incorporates all the specifications from the client and the experts. The project resource planning determines the various resources that are required for the completion of the project. These include finances, human resource, material resources, among others. In planning for the resources, the project managers identify the needed resources, their availability, key resource suppliers and the coordination of the availed resources. The stakeholder participation estimates the costs associated with the completion of the whole project. This budgeting involves various key activities like project costing where all the cost centres are identified with an estimate of the costs in completing the activities in that centre. This is followed by fund acquisition which entails searching for the sources of funds either from own financing (government financing), or from donor funding or borrowing. Lastly, the acquired funds are allocated appropriately to the cost centres.

On the other side, the conceptual framework shows the dependent variable which is project implementation. This is to be measured by how well the project identify and develop the team players, how different tasks are assigned to different teams and the execution of the project plans. In addition, the conceptual framework shows the intervening variables which include government regulations and project management skills.

\section{Methodology}

\subsection{Research Design}

This research study adopted a descriptive research design to investigate project planning and its impact on project implementation. A descriptive research design allows for an in-depth analysis and perception of a sure phenomenon as it exists in the existing condition (Elise, et al., 2016). In descriptive research design, goals are predetermined permitting data collection relevant and sufficient to the study problem (Elise, et al., 2016). By combining quantitative and qualitative data collection procedures, descriptive research design enabled the researcher to gather exhaustive data in a way that reduces cost of the information collection.

\subsection{Target Population and Sample Size}

A study population is understood as a well-defined or distinct set of people, crew of things, households, firms, services or occasions which are being investigated (Banerjee \& Chaudhury, 2010). Thus, the population must meet certain conditions, which was the researcher's focus and was homogenous. The target population of this study was 143 composed by 7 donors, 9 project employees and 127 beneficiaries of the Rwanda National Union of Deaf (RNUD. The sample size was determined using Yamane (1967) formula

$$
n=\frac{N}{\left(1+N e^{2}\right)}=\frac{127}{1+127 * 0.05^{2}} \approx 96
$$

A simple random sampling technique was applied to select respondents, where each respondent had equal chance of being selected. Data was collected using structured questionnaires. The data obtained were analyzed using SPSS version 21. 


\section{IV.Results and Discussions}

\subsection{Demographic Characteristics of Respondents}

The researcher collected the information about the demographic characteristics of respondents which are gender, age, marital status, and time spent in RNUD Project in order to facilitate the interpretation.

Table 1: Summary on background information of respondents

\begin{tabular}{|l|l|l|}
\hline & Frequency & Percentage \\
\hline Gender of respondents: Male & 64 & 57.1 \\
Female & 48 & 42.9 \\
\hline Age of Respondents: Below 25 years & 19 & 17 \\
25-35 years & 47 & 42 \\
35-45 years & 42 & 37.6 \\
Above 45 years & 4 & 3.6 \\
\hline Marital status: Married & 90 & 80.4 \\
Single & 20 & 17.9 \\
Divorced & 2 & 1.8 \\
\hline Time Spent in RNUD: Below 5 years & 20 & 17.9 \\
5-10 years & 46 & 41.1 \\
10-15 years & 29 & 25.9 \\
Above 15 years & 17 & 15.2 \\
\hline
\end{tabular}

Source: Primary Data, 2020

\subsection{Presentation of Findings}

The results of the study presented in this section are presented in regard to study variables which are project scope planning, project resource planning, stakeholder participation and project implementation in Rwanda National Union of Deaf (RNUD) Project. The results are related to the study specific objectives in statement presented in regard to each variables of the study. The perceptions of the respondents are analyzed using descriptive, inferential statistics, and multiple regressions in regard to statement related to project scope planning, project resource planning and stakeholder participation.

Table 2: Statement regarding project scope planning

\begin{tabular}{llllllll}
\hline Project Scope Identification & $\mathbf{S A}$ & $\mathbf{A}$ & $\mathbf{N}$ & $\mathbf{D}$ & $\mathbf{S D}$ & Mean & \multirow{2}{*}{ Std. } \\
\cline { 2 - 6 } & $\mathbf{\%}$ & $\mathbf{\%}$ & $\mathbf{\%}$ & $\mathbf{\%}$ & $\mathbf{\%}$ & & \\
\hline Promotes need assessment for implementation & 76.8 & 4.5 & 8.0 & 8.0 & 2.7 & 4.446 & 1.106 \\
Enhances beneficiary specifications for implementation & 87.5 & 5.4 & 3.6 & 1.8 & 1.8 & 4.750 & 0.765 \\
Facilitates effective project design for implementation & 85.7 & 6.3 & 3.6 & 2.7 & 1.8 & 4.714 & 0.810 \\
Affects project starting time for implementation & 44.6 & 8.9 & 5.4 & 4.5 & 36.6 & 3.205 & 1.836 \\
Promotes identification of participants & 81.3 & 9.8 & 4.5 & 2.7 & 1.8 & 4.661 & 0.833 \\
Enhances collective decision making for implementation & 76.8 & 13.4 & 4.5 & 3.6 & 1.8 & 4.598 & 0.875 \\
Affects timely implementation & 81.3 & 8.9 & 4.5 & 2.7 & 2.7 & 4.634 & 0.900 \\
Total Mean & & & & & & $\mathbf{4 . 4 3 0}$ &
\end{tabular}

Source: Primary Data, 2020

Table 2 demonstrate that mean is 4.750 and SD is 0.765 at $87.5 \%$ of respondents who strongly agreed that regarding project scope planning affect Project scope planning enhances beneficiary specifications for implementation. The mean is 4.714 and SD is.810 at $85.7 \%$ of respondents strongly agreed that regarding project scope planning affect Project scope planning facilitates effective project design for implementation. The mean is 4.661 and SD is 0.833 at $81.3 \%$ of respondents strongly agreed that regarding project scope planning affect Project scope planning promotes identification of project participants. The mean is 4.634 and SD is 0.900 at $81.3 \%$ of respondents strongly agreed that regarding project scope planning affect Project scope planning affect timely implementation of project activities. The mean is 4.446 and SD is 1.106 at $76.8 \%$ of respondents strongly agreed that regarding project scope planning affect Project scope planning promotes need assessment for implementation. The mean is 4.598 and SD is 0.875 at $76.8 \%$ of respondents strongly agreed that regarding project scope planning affect Project scope planning enhance collective decision making for implementation. The mean is 3.205 and SD is 1.836 at $44.6 \%$ of respondents strongly agreed that regarding project scope planning affect Project scope planning affect project starting time for implementation. Thus, since the total mean is 4.430 implies that project scope planning has high effect on project implementation in RNUD Project in Kicukiro District, Rwanda.

In an interview with one of the employees of RNUD project conducted on $3^{\text {rd }}$ October, he started that participatory planning is the key stone for the project implementation in RNUD because the beneficiaries of the project are consulted while doing project planning so that during the implementation of the project it becomes more easy.

The findings of this study asserting that project scope planning has high effect on implementation of RNUD Project are 
supported by the study conducted by Asha (2014) who investigated how effective planning of integrated Development Plans impacted on their implementation in South Africa. The finding has proved that there is a positive effect of planning the scope of the project to its implementation.

Table 3: Statement regarding project resource planning

\begin{tabular}{llllllll}
\hline Project Resource Planning & SA & $\mathbf{A}$ & $\mathbf{N}$ & $\mathbf{D}$ & SD & Mean & Std. D \\
\cline { 2 - 7 } & $\mathbf{\%}$ & $\mathbf{\%}$ & $\mathbf{\%}$ & $\mathbf{\%}$ & $\mathbf{\%}$ & & \\
\hline Promotes resource availability & 84.8 & 7.1 & 1.8 & 3.6 & 2.7 & 4.679 & 0.892 \\
Enhances supplier identification & 88.4 & 5.4 & 1.8 & 3.6 & .9 & 4.768 & 0.735 \\
Facilitates resource coordination & 83.9 & 11.6 & 1.8 & 1.8 & .9 & 4.759 & 0.661 \\
Increases resource utilization & 77.7 & 11.6 & 4.5 & 1.8 & 4.5 & 4.562 & 0.993 \\
Helps to track resource capability & 75.0 & 14.3 & 6.3 & 2.7 & 1.8 & 4.580 & 0.866 \\
Help to keep project on its budget & 52.7 & 19.6 & 10.7 & 8.0 & 8.9 & 3.991 & 1.332 \\
Helps to maximize employees' time & 71.4 & 10.7 & 6.3 & 7.1 & 4.5 & 4.375 & 1.156 \\
Total Mean & & & & & & $\mathbf{4 . 5 3 1}$ & \\
\hline
\end{tabular}

Source: Primary Data, 2020

The results indicate that there is stronger tendency of 4.768 mean and SD is 0.735 at $88.4 \%$ of respondents strongly agreed that project resource planning affect project resource planning enhances supplier identification. There is stronger tendency of 4.679 and SD is 0.892 at $84.8 \%$ of respondents strongly agreed that regarding project resource planning affect project resource planning promotes resource availability. There is stronger tendency of 4.7589 mean and SD equals 0.661 whereby $83.9 \%$ of respondents strongly agreed that regarding project resource planning affect project resource planning facilitates resource coordination. There is stronger tendency of 4.562 mean and SD is 0.993 whereby $77.7 \%$ of respondents strongly agreed that regarding project resource planning affects project resource planning increases effective resource utilization. There is stronger tendency of 4.5804 mean and SD is 0.866 whereby $75.0 \%$ of respondents strongly agreed that regarding project resource planning affect project resource planning helps to track resource capability. There is stronger tendency of 4.375 mean and SD is

1.156 whereby $71.4 \%$ of respondents strongly agreed that regarding project resource planning affect Project resource planning helps to maximize employees' time. There is stronger tendency of 3.991 mean and SD is 1.332 whereby $52.7 \%$ of respondents strongly agreed that regarding project resource planning affect Project resource planning help to keep project on its budget, the result also shows that the highest mean is 3.991 while the lowest mean is 4.768. The total mean is 1.472 which shows that project resource planning has a high effect on project implementation in RNUD Project in Kicukiro District, Rwanda.

On $4^{\text {th }}$ October the researcher conducted an interview with one of the employees of RNUD project. The interviewee stated that both capital and human resource planning before the implementation process of their project are very crucial parts of the project that have enhance performance and success of the project in the last 5 years. He also stated that due to project resource planning the project have managed to train a hundreds of the people in sign language including the Lawyers from BAR association who are currently being trained in sign language.

The finding of this study which stipulate that project resource planning has a high effect on project implementation in RNUD Project is supported by the findings of Igwe and Ude (2014) on project planning and implementation in Nigeria. This research aimed at exploring the link between project planning and implementation in line with international best practices. They carried out a documentary review of literature. The finding pointed out that there exist different literature emphasizing the link between project planning and implementation.

Table 4: Statement regarding Stakeholder Participation

\begin{tabular}{|c|c|c|c|c|c|c|c|}
\hline \multirow[t]{2}{*}{ Stakeholder Participation } & $\mathbf{S A}$ & $\mathbf{A}$ & $\mathbf{N}$ & $\mathbf{D}$ & SD & \multirow[t]{2}{*}{ Mean } & \multirow[t]{2}{*}{ Std. } \\
\hline & $\overline{\%}$ & $\%$ & $\%$ & $\%$ & $\%$ & & \\
\hline Eases communication for budgeting data & 90.2 & 3.6 & 1.8 & 2.7 & 1.8 & 4.777 & 0.768 \\
\hline Increases beneficiary satisfaction & 78.6 & 13.4 & 4.5 & 1.8 & 1.8 & 4.652 & 0.802 \\
\hline Initiates change to enhance implementation & 91.1 & 2.7 & 2.7 & 1.8 & 1.8 & 4.795 & 0.737 \\
\hline Facilitates control of activities & 82.1 & 7.1 & 3.6 & 3.6 & 3.6 & 4.607 & 0.980 \\
\hline Increases sense of project ownership & 91.1 & 3.6 & 2.7 & .9 & 1.8 & 4.812 & 0.691 \\
\hline Facilitates consultation for decision making & 85.7 & 8.0 & 2.7 & 1.8 & 1.8 & 4.741 & 0.756 \\
\hline Puts decisions of decision makers into actions & 77.7 & 10.7 & 6.3 & 3.6 & 1.8 & 4.589 & 0.896 \\
\hline Total Mean & & & & & & 4.710 & \\
\hline
\end{tabular}

Source: Primary Data, 2020

The results presented in Table 4 indicate that the stronger tendency of mean which is 4.795 and SD is 0.737 at $91.1 \%$ of respondents strongly agreed that regarding stakeholder participation eases communication for budgeting data. The stronger tendency of mean which is 4.812 and SD is 0.691 at $91.1 \%$ of respondents strongly agreed that regarding stakeholder participation increases beneficiary satisfaction. The stronger tendency of mean which is 4.777 and SD is 
0.768 at $90.2 \%$ of respondents strongly agreed that regarding stakeholder participation initiates change to enhance implementation. The stronger tendency of mean which is 4.741 and SD is 0.756 at $85.7 \%$ of respondents strongly agreed that regarding stakeholder participation facilitates control of activities. The stronger tendency of mean which is 4.607 and SD is 0.980 at $82.1 \%$ of respondents strongly agreed that regarding stakeholder participation increases sense of project ownership. The stronger tendency of mean which is 4.652 and SD is 0.802 at $78.6 \%$ of respondents strongly agreed that regarding stakeholder participation facilitates consultation for decision making. The stronger tendency of mean which is 4.589 and SD is 0.896 at $77.7 \%$ of respondents strongly agreed that regarding stakeholder participation puts decisions of decision makers into actions. The result also shows that the highest mean is 4.589 while the lowest mean is 4.812 because the highest score is 5 where even the total mean tends to 4.710 of mean which implies that the stakeholder participation has a high effect on project implementation in RNUD Project in Kicukiro District, Rwanda. The researcher also sought to establish the relationship between project planning and project implementation as the general objective. The indicators used for measuring project implementation included team development, task assignment and plan execution. The results are therefore presented in the following paragraphs along these indicators. The results of the study presented here are collected from the views and perceptions of respondents which are correlated to prove the relationship between the variables of the study and comprise correlation between variables of project planning, between variables of project implementation and between variables between project planning and implementation in RNUD Project in Kicukiro District, Rwanda.

Table 5: Statement regarding project implementation

\begin{tabular}{llllllll}
\hline Project Implementation & SA & A & N & D & SD & Mean & \multirow{2}{*}{ Std. } \\
\cline { 2 - 6 } & $\%$ & $\%$ & $\%$ & $\%$ & $\%$ & & \\
\hline Gives opportunity to see plans becoming a reality & 77.7 & 16.1 & 2.7 & 1.8 & 1.8 & 4.661 & 0.777 \\
Facilitates team development in a project & 77.7 & 11.6 & 6.3 & 2.7 & 1.8 & 4.607 & 0.863 \\
Enhances accomplishment of task assignment & 67.9 & 6.3 & 3.6 & 13.4 & 8.9 & 4.107 & 1.435 \\
Promotes project plan execution & 68.8 & 20.5 & 6.3 & 2.7 & 1.8 & 4.518 & 0.870 \\
Puts action plans into operation & 45.5 & 10.7 & 24.1 & 17.0 & 2.7 & 3.795 & 1.260 \\
Enhances tangible changes and improvements & 56.3 & 16.1 & 18.8 & 7.1 & 1.8 & 4.179 & 1.084 \\
Enhance M\&E for transparency in regard to finance & 67.0 & 17.9 & 8.9 & 4.5 & 1.8 & 4.437 & 0.956 \\
Total Mean & & & & & & $\mathbf{4 . 3 2 9}$ & \\
\hline
\end{tabular}

Source: Primary Data, 2020

The results presented Table 5 show that stronger tendency of mean which is 4.661 and SD is 0.777 at $77.7 \%$ of respondents strongly agreed that regarding project implementation affect Project implementation gives opportunity to see plans becoming a reality. The stronger tendency of mean which is 4.607 and SD is 0.863 at $77.7 \%$ of respondents strongly agreed that regarding project implementation affect Project implementation facilitates team development in a project. The stronger tendency of mean which is 4.107 and SD is 1.435 at $67.9 \%$ of respondents strongly agreed that regarding project implementation affect Project implementation enhances accomplishment of task assignment. The mean is 4.518 and SD is 0.870 at $68.8 \%$ of respondents strongly agreed that regarding project implementation affect project implementation promotes project plan execution. The mean is 4.437 and SD is 0.956 at $67.0 \%$ of respondents strongly agreed that regarding project implementation affect Project implementation enhance M\&E for transparency in regard to finance. The mean is 4.179 and SD is 1.084 at $56.3 \%$ of respondents strongly agreed that regarding project implementation affect Project implementation enhances tangible changes and improvements. The mean is 3.7946 and SD is 1.260 at $45.5 \%$ of respondents

strongly agreed that regarding project implementation affect Project implementation puts action plans into operation. Thus, the highest score is 5 and the total mean is 4.329 which imply that project planning has a high effect on implementation of the project in RNUD Project in Kicukiro District, Rwanda.

Table 6: Regression Model Summary

\begin{tabular}{lllll}
\hline Model & $\mathrm{R}$ & R Square & Adjusted R Square & Std. Error of the Estimate \\
\hline 1 & $.943^{\mathrm{a}}$ & .890 & .887 & .39801 \\
\hline a. Predictors: (Constant), Stakeholder participation, Project scope planning, Project resource planning
\end{tabular}

Source: Primary Data, 2020

The results in Table 6 prove that the $\mathrm{R}$ coefficient 0.943 shows that project planning has a relationship with team development of RNUD Project. The coefficient of determination $0.890 \mathrm{R}$ square also indicates that project planning explains $89.0 \%$ of the progress variability in team development of RNUD Project. This implies that predictors of project planning such as stakeholder participation, project scope planning and project resource planning affects progress of $89.0 \%$ in team development of RNUD Project in Kicukiro District, Rwanda. 
Table7: Analysis of Variance (ANOVA) Table for team development

\begin{tabular}{llllll}
\hline Model & Sum of Squares & Df & Mean Square & F & Sig. \\
\hline Regression & 138.382 & 3 & 46.127 & 291.943 & $.000^{\mathrm{b}}$ \\
Residual & 17.109 & 108 & .158 & & \\
Total & 155.491 & 111 & & & \\
\hline
\end{tabular}

a. Dependent Variable: Team development

b. Predictors: (Constant), Stakeholder participation, Project scope planning, Project resource

Source: Primary Data, 2020

The results of Table 7 proved that there is a significant relationship between project planning and team development due to the fact that the calculated 0.000 significance level is less than 0.05 significance level $(0.000$

<0.05). Therefore, the statistical model looks forward to the relationship between project planning and team development is positive significant in RNUD Project in Kicukiro District, Rwanda.

Table 8: Regression Coefficients Table for team development

\begin{tabular}{|c|c|c|c|c|c|}
\hline \multirow[t]{2}{*}{ Model } & \multicolumn{2}{|c|}{ Unstandardized Coefficients } & Standardized & \multirow[t]{2}{*}{$\mathrm{t}$} & \multirow[t]{2}{*}{ Sig. } \\
\hline & B & Std. Error & Beta & & \\
\hline (Constant) & -.053 & .073 & & -.724 & .471 \\
\hline Project scope planning & .290 & .052 & .294 & 5.560 & .000 \\
\hline Project resource planning & .022 & .064 & .023 & 4.336 & .003 \\
\hline Stakeholder participation & 651 & .060 & .683 & 10.917 & .000 \\
\hline
\end{tabular}

Source: Primary Data, 2020

The findings in Table 8 have shown that predictors of project planning have positive coefficients that enhance the positive impact on team development of RNUD project in Kicukiro district. The progress analysis shows that there is positive significant project planning and team development, as all calculated $\mathrm{p}$ values are much less than 0.05 of significance level. Therefore, the coefficients provide a regression model, $\mathrm{Y}=\beta 0+\beta 1 \mathrm{X} 1+\beta 2 \mathrm{X} 2+\beta 3 \mathrm{X} 3+\beta$. Therefore, it turns into $\mathrm{Y}=-0.53+0.290 \mathrm{X}_{1}+0.022 \mathrm{X}_{2}+0.651 \mathrm{X}_{3}$, this regression equation suggests that there is a positive significant relationship between project planning and project development of RNUD Project in Kicukiro District. The objective established to indicate the relationship between project scope planning and team development proves that there is a positive and significant relationship $(b=0.290$ and $p=0.000)$ which is lesser than 0.05 level of significance; the second objective established to indicate the relationship between project resource planning and team development has a positive and significant relationship $(b=0.022$ and $p=0.003)$ which is lesser than 0.05 level of significance; the third objective established to indicate the relationship between stakeholder participation and Team development it has a positive, significant relationship $(b=0.651$ and $p=0.000)$ that is much less than

0.05 significance level. Therefore, it implies that there is a significant positive relationship between Project Planning and Team development of RNUD Project in Kicukiro District.

Table 9: Regression Model Summary for task assignment

\begin{tabular}{cccc}
\hline Model R & R Square & Adjusted R Square & Std. Error of the Estimate \\
\hline $.849^{\mathrm{a}}$ & .721 & .713 & .62859 \\
\hline
\end{tabular}

Source: Primary Data, 2020

The results in Table 9 prove that the $\mathrm{R}$ coefficient 0.849 shows that Project Planning has a relationship with Task assignment of RNUD Project. The coefficient of determination $0.721 \mathrm{R}$ square also indicates that Project

Planning explains $72.1 \%$ of the progress variability in Task assignment of RNUD Project. Thus, implies that predictors of Project Planning such as Stakeholder participation, Project scope planning and Project resource planning that affect progress $72.1 \%$ of task assignment of Rwanda National Union of Deaf (RNUD) Project in Kicukiro District, Rwanda. The results of this study have revealed that the coefficient of determinations $.721 \mathrm{R}$ square indicates that project planning explains $72.1 \%$ of progress in task assignment of Rwanda National Union of Deaf (RNUD) Project which is supported by the study of Serrador (2013) which revealed that the average value for $\mathrm{R}^{2}$ obtained is 0.33 between project planning and efficiency and an average $\mathrm{R}^{2}$ of 0.34 between project planning and the overall. 
Table 10: Analysis of Variance (ANOVA) for task assignment

\begin{tabular}{llllll}
\hline Model & Sum of Squares & Df & Mean Square & F & Sig. \\
\hline Regression & 110.389 & 3 & 36.796 & 93.125 & $.000^{\mathrm{b}}$ \\
Residual & 42.674 & 108 & .395 & & \\
Total & 153.063 & 111 & & & \\
\hline
\end{tabular}

a. Dependent Variable: Task assignment

b. Predictors: (Constant), Stakeholder participation, Project scope planning, Project resource Source: primary data, 2020

The results in Table 10 prove that there is a vast relationship between project planning and task assignment due to the fact that the calculated significance value .000 is less than 0.05 significance level (calculated .000 sig.). Therefore, the statistical model expects the relationship between project planning and task assignment is positive significant in RNUD Project in Kicukiro District, Rwanda.

Table 11. Regression Coefficients for task assignment

\begin{tabular}{|c|c|c|c|c|c|}
\hline \multirow[t]{2}{*}{ Model } & \multicolumn{2}{|c|}{ Unstandardized Coefficients } & \multirow{2}{*}{$\begin{array}{l}\text { Standardized } \\
\text { Coefficients } \\
\text { Beta }\end{array}$} & \multirow[t]{2}{*}{$\mathrm{t}$} & \multirow[t]{2}{*}{ Sig. } \\
\hline & $\mathrm{B}$ & Std. Error & & & \\
\hline (Constant) & .162 & .116 & & 1.401 & .164 \\
\hline Project scope planning & .383 & .082 & .392 & 4.657 & .000 \\
\hline Project resource planning & .131 & .101 & .138 & 1.296 & .001 \\
\hline Stakeholder participation & .364 & .094 & .385 & 3.864 & .000 \\
\hline
\end{tabular}

a. Dependent Variable: Task assignment

Source: primary data, 2020

The findings in Table 11 show that predictors of project planning have positive coefficients that enhance positive effect on Rwanda National Union of Deaf (RNUD) project in Kicukiro District. The progress analysis indicates that there is a big positive and significant between projects planning and task assignment due to the reality that all calculated $\mathrm{p}$ values are much less than $0.05 \mathrm{sig}$. level. Therefore, the coefficients give regression model, $\mathrm{Y}=\beta_{0}+\beta_{1} \mathrm{X}_{1}+\beta_{2} \mathrm{X}_{2}+\beta_{3} \mathrm{X}_{3}+$ $\beta$. Therefore, it will become $Y=-.162+.383 \mathrm{X}_{1}+.131 \mathrm{X}_{2}+.364 \mathrm{X} 3$, this regression equation suggests that there is a positive significant between project planning and task assignment of Rwanda National Union of Deaf (RNUD) Project in Kicukiro District, Rwanda.

The sought to investigate the relationship between project scope planning and task assignment proves that there is a positive and significant relationship $(b=.383$ and $\mathrm{p}=.000)$ which is lesser than 0.05 level of significance; the second objective established to indicate the relationship between project resource planning and Task assignment has a positive and significant relationship ( $\mathrm{b}=-.131$ and $\mathrm{p}=.001$ ) which is lesser than 0.05 level of significance; the third objective established to indicate the relationship between stakeholder participation and Task assignment has a positive and significant relationship $(b=.364$ and $p=.000)$ which is lesser than 0.05 level of significance. Thus, implies that there is a positive significant relationship between project planning and task assignment of Rwanda National Union of Deaf (RNUD) Project in Kicukiro District, Rwanda.

Table 12: Regression Correlations analysis between project planning and implementation

Team development Task assignment Plan execution

\begin{tabular}{|c|c|c|c|c|c|}
\hline \multirow[t]{2}{*}{$\begin{array}{l}\text { Project } \\
\text { planning }\end{array}$} & scope & $\begin{array}{l}\text { Pearson Correlation } \\
\text { Sig. (2-tailed) }\end{array}$ & $\begin{array}{l}.821^{* *} \\
.000\end{array}$ & $\begin{array}{l}.787^{* *} \\
.000\end{array}$ & $\begin{array}{l}.848^{* *} \\
.000\end{array}$ \\
\hline & & $\mathrm{N}$ & 112 & 112 & 112 \\
\hline \multirow[t]{2}{*}{$\begin{array}{l}\text { Project } \\
\text { planning }\end{array}$} & resource & $\begin{array}{l}\text { Pearson Correlation } \\
\text { Sig. (2-tailed) }\end{array}$ & $\begin{array}{l}.834^{* *} \\
.000\end{array}$ & $\begin{array}{l}.772^{* *} \\
.000\end{array}$ & $\begin{array}{l}.858^{* *} \\
.000\end{array}$ \\
\hline & & $\mathrm{N}$ & 112 & 112 & 112 \\
\hline \multirow[t]{2}{*}{$\begin{array}{l}\text { Stakeholder } \\
\text { participation }\end{array}$} & & $\begin{array}{l}\text { Pearson Correlation } \\
\text { Sig. (2-tailed) }\end{array}$ & $\begin{array}{l}.922^{* *} \\
.000\end{array}$ & $\begin{array}{l}.795^{* *} \\
.000\end{array}$ & $\begin{array}{l}.872^{* *} \\
.000\end{array}$ \\
\hline & & $\mathrm{N}$ & 112 & 112 & 112 \\
\hline
\end{tabular}

**. Correlation is significant at the 0.01 level (2-tailed).

Source: Primary Data, 2020

The findings in Table 4.6 reveal that there is a positive significant relationship between project scope planning and 
team development $(\mathrm{p}=.821$ and $\mathrm{sig}=.000)$, between project scope planning and task assignment $(\mathrm{p}=.787$ and $\mathrm{sig}=.000)$, between project scope planning and plan execution $(\mathrm{p}=.848$ and $\mathrm{sig}=.000)$ between project resource planning and team development $(\mathrm{p}=.834$ and $\mathrm{sig}=.000)$ between project resource planning and task assignment $(\mathrm{p}=.772$ and $\mathrm{sig}=.000)$ between project resource planning and plan execution $(\mathrm{p}=.858$ and $\mathrm{sig}=.000)$ between stakeholder participation and team development $(\mathrm{p}=.922$ and $\mathrm{sig}=.000)$, between stakeholder participation and task assignment $(\mathrm{p}=.795$ and sig=.000) between stakeholder participation and plan execution $(\mathrm{p}=.872$ and sig=.000) because all calculated $\mathrm{p}$ - values are less than 0.01 level of significance. Thus, implies that there is a positive significant relationship between project Planning and implementation of Rwanda National Union of Deaf (RNUD) Project in Kicukiro District, Rwanda.

The finding of this study have revealed that there is a positive and significant relationship between project planning and implement of Rwanda National Union of Deaf (RNUD) Project which is supported by the study of Zwikael \& Meredith (2019) conducted a research investigating implications of project planning on the overall performance of project in commercial projects and its correlation analysis revealed that the Pearson's coefficient is 0.23 between project planning and project performance. This finding is also supported by the results of the study from Naeem et al., (2018), who performed a study on the impact of project planning on project success and the results have proven a positive and significant relationship between project planning and project success with a correlation of 0.555 . The research also used moderate regression analysis to test the hypothesis where the results showed the model to be significant with p-value less than $5 \%$ level of significance.

The results above are also supported by the findings of the study conducted by Ong'aro and Asumptah (2017) on the determinant of the successful implementation of housing projects in Rwanda. Thus, the factors that were investigated like top management, communication channels and project planning were found to have a positive and significant correlation with project implementation with $\mathrm{r}=0.318$ and $\mathrm{p}$-value of less than $5 \%$ level of significance.

Table 13 Regression Model Summary on plan execution

\begin{tabular}{cccc}
\hline $\begin{array}{lll}\text { Model } \\
\text { R }\end{array}$ & R Square & Adjusted R Square & Std. Error of the Estimate \\
\hline $.928^{\mathrm{a}}$ & .860 & .856 & .44300 \\
\hline a. Predictors: (Constant), Stakeholder participation, Project scope planning, Project resource planning
\end{tabular}

Source: primary data, 2020

The results in Table 13 prove that the $\mathrm{R}$ coefficient .928 shows that project planning has a relationship with plan execution of Rwanda National Union of Deaf (RNUD) Project. The coefficient of determination .860 R- square also indicates that project planning explains $86.0 \%$ of the progress variability in Plan execution of Rwanda National Union of Deaf (RNUD) Project. Thus, implies that predictors of project planning such as stakeholder participation, project scope planning and project resource planning that affect progress $86.0 \%$ of plan execution of Rwanda National Union of Deaf (RNUD) Project in Kicukiro District, Rwanda.

The above results are supported by the study of Kanyago and Shukla (2017) which were conducted on the role of project management skills on construction projects performance in Rwanda and the results of the study have revealed that project management skills influences project performance with $\mathrm{R}^{2}$ of 0.306 . Thus, implies that project planning skills have a significant relation with project performance.

Table 14: Analysis of Variance (ANOVA) on plan execution

\begin{tabular}{llllll}
\hline Model & Sum of Squares & Df & Mean Square & F & Sig. \\
\hline Regression & 130.484 & 3 & 43.495 & 221.629 & $.000^{\mathrm{b}}$ \\
Residual & 21.195 & 108 & .196 & & \\
Total & $\mathbf{1 5 1 . 6 7 9}$ & $\mathbf{1 1 1}$ & & & \\
\hline
\end{tabular}

a. Dependent Variable: Plan execution

b. Predictors: (Constant), Stakeholder participation, Project scope planning, Project resource planning

Source: Primary Data, 2020

The findings in Table 14 reveal that there is a significant and positive relationship between project planning and plan execution, as the calculated significance value is 0.00 which is less than 0.05 level of significance (calculated sig. value $0.000<0.05$ critical level). Therefore, the statistical model shows that the relationship between project planning and plan execution is positive and significant in Rwanda National Union of Deaf (RNUD) Project in Kicukiro District, Rwanda. 
Table 15. Regression Coefficients for plan execution

\begin{tabular}{lllllll}
\hline Model & \multicolumn{2}{l}{$\begin{array}{l}\text { Unstandardized } \\
\text { Coefficients }\end{array}$} & \multicolumn{2}{l}{$\begin{array}{l}\text { Standardized } \\
\text { Coefficients }\end{array}$} & & Sig. \\
\cline { 2 - 5 } & $\mathrm{B}$ & Std. Error & \multicolumn{2}{l}{ Beta } & & \\
\hline (Constant) & -.094 & .082 & & -1.146 & .254 \\
Project scope planning & .361 & .058 & .371 & 6.221 & .000 \\
Project resource planning & .211 & .071 & .223 & 2.958 & .004 \\
Stakeholder participation & .382 & .066 & .406 & 5.758 & .000 \\
\hline
\end{tabular}

Dependent Variable: Plan execution

Source: Primary Data, 2020

The findings in Table 15 indicate that the predictors of project planning have positive coefficients that enhance positive effect on the progress of the execution of the plan of the Rwanda National Union of Deaf (RNUD) Project in Kicukiro District. Progress analysis suggests that there is a positive and significant relationship between project planning and plan execution, as all calculated $\mathrm{p}$ values are much less than $0.05 \mathrm{sig}$. level. Therefore, the coefficients provide a regression model, $Y=\beta 0+\beta 1 X_{1}+\beta 2 X_{2}+\beta 3 X_{3}+\beta$. Therefore, it becomes $Y=-.094+.361 X_{1}+.211 X_{2}+.382 X_{3}$, this regression equation shows that there is a positive and significant relationship between project planning and plan execution of Rwanda National Union of Deaf (RNUD) Project in Kicukiro District, Rwanda.

The first objective established to indicate the relationship between project scope planning and plan execution proves that there is a positive and significant relationship $(b=.361$ and $p=.000)$ which is lesser than 0.05 level of significance; the second objective established to indicate the relationship between project resource planning and plan execution has a positive and significant relationship $(b=-.211$ and $p=.004)$ which is lesser than 0.05 level of significance; the third objective established to indicate the relationship between stakeholder participation and Plan execution has a positive and significant relationship $(b=.382$ and $p=.000)$ which is lesser than 0.05 level of significance. Thus, implies that there is a positive significant relationship between project planning and plan execution of Rwanda National Union of Deaf (RNUD) Project in Kicukiro District, Rwanda.

\subsection{Discussion}

This research was centered on the impact of project planning on the successful implementation of project in Rwanda, with a case of Rwanda National Union of Deaf (RNUD). This objective was mainly analyzed among three specific research objectives. The independent variables, project planning, was measured using project scope planning, resource planning and stakeholders' participation. These three formed the basis for the three specific objectives. In the first objective, the research sought to establish the impact of project scope planning on the implementation of project in Rwanda. The results revealed that project scope planning is an important factor that needs to be incorporate in the planning process. It helps in making the project successful especially during the execution stage.

The total mean score implied that project scope planning has high effect on project implementation. The findings of this study asserting that project scope planning has high effect on implementation of Rwanda National Union of Deaf (RNUD) Project are supported by the study conducted by Asha (2014) who investigated how effective planning of integrated Development Plans impacted on their implementation in South Africa. The finding has proved that there is a positive effect of planning the scope of the project to its implementation. It was also found that project scope planning is positively and significantly related to team development, task assignment and plan execution. This is consistent with research work by Zwikael \& Meredith (2019).

With respect to project resource planning, it was found that the overall mean score was high which showed that project resource planning has a high effect on project implementation in Rwanda National Union of Deaf (RNUD) Project in Kicukiro District, Rwanda. Moreover, project resource planning was also found to have positive and significant effect on the team development, task assignment and plan execution. Lastly, it was found that improving stakeholders' participation in projects ensures that the project incorporates their views and interest. Hence, the project implementation becomes possible when there increased participation from the stakeholders. In addition, the stakeholders' participation was found to be significantly and positively related to team development, task assignment and plan execution. These findings are supported by the results of the study from other scholars like Naeemet al., (2018), Ong'aro and Asumptah (2017) and Kanyago and Shukla (2017). It is therefore important for project managers and donors to have thorough project plans that should cover project scope planning, resource planning and stakeholders participation. In this way, they can be able to improve the efficiency of the implementation process of the project they are carrying.

\section{Conclusion and Recommndations \\ 5.1 Conclusion}

This research focused on finding out the effect of project planning on the implementation of projects in Rwanda. In particular, Rwanda National Union of Deaf was used as the case for easy data gathering and analysis. The main variables of study stated in this research were project planning as measured by three key indicators, namely, project scope planning, project resource planning and stakeholders' participation. On the other hand the independent variable was implementation of the project, as measured by team development, task assignment and plan execution. The proposed effect was that there is a positive and significant effect of project planning on project implementation. To establish this, 
the researcher analyzed various responses obtained through questionnaire and interview.

The results of this research showed that in order to have an effective project implementation, there is need for a good planning that should also be thorough. In this regard, project scope planning was found to have a positive effect on project implementation. The findings were in line with those of Zwikael \& Meredith (2019)who conducted a research investigating implications of project planning on the overall performance of project in commercial projects and the findings have shown there is significant correlation between project planning and project performance.

Similarly, the findings on the resource planning on project implementation revealed a strong, positive and significant relation between the variables. Naeem, Khanzada, Mubashir and Sohail (2018) carried an empirical research with risk management and organizational revealed that there is a positive and significant relationship between project planning and project success.

\subsection{Recommendations}

Basing on the results of the study, the researcher would like to recommend to project employees to equip the beneficiaries with more planning skills so that the planning process should be more participatory rather than consultative in the process of project planning. The researcher would also like to recommend to the project management to enhance the process of project planning by including the project beneficiaries not only in planning process rather be involved in all process of project including monitoring, control and implementation.

The researcher would like to recommend to the donors of the project to follow the whole process of project planning and implementation to advocate for the beneficiaries of the project and enhance the success of Rwanda National Union of Deaf (RNUD) Project. The researcher can never forget to provide recommendations to project beneficiaries to be part and parcel of project planning and implementation process of Rwanda National Union of Deaf (RNUD) Project to enhance its performance.

Basing on the results of the study, the researcher would like to recommend to the community to be part of the communication and advocacy of the People with Disabilities, most especially Deaf Persons through upholding and respect the rights of Deaf Persons and enhance the knowledge of sign language so that the communication of Deaf Persons becomes more easier to communicate in the community. The study has also revealed that there is a significant and positive relationship between stakeholder participation and implementation of the project through task assignment, team development and plan execution which means that the project stakeholders are recommended to participate fully in consultative meeting, communication process and increase the sense of ownership of the project to ensure satisfaction of the project satisfaction and hence project success due to effective project implementation.

Finally, the researcher recommends that policy makers and practitioners would embrace project planning holistically if they want to have successful projects. Policy makers can put measures that can ensure that projects undertaken in the public sectors and in other sectors undertake a thorough scope definition, resource planning and ensure stakeholders participation. Just like there are regulations that govern different practices like auditing, accounting and others, there is need for sound regulatory framework or manuals that guide the formulation of projects and especially the planning phase. This would ensure that the high rate of project failures is reduced. Similarly, practitioners ought to help in formulating working guideline for new and existing project managers in regard to project planning.

\section{References}

[1].Abraham, A. (2014). Project Planning and Management: An Aspect of Development. Hamburg, Germany: Anchor Academic Publishing.

[2].Ajam, M. A. (2015). Applied Project Management. USA: Author House.

[3].Akdeniz, C. (2015). Project Design Explained: Project Management Books. Germany: Baderstrasse.

[4].Asha, A. A. (2014). Towards Effective Planning and Implementation of the Local Development Initiatives in Limpopo Province, South Africa. Mediterranean. Journal of Social Sciences, 5(20), 398-409.

[5].Banerjee, A\& Chaudhury, S. (2010). Statistics without tears: Populations and samples. Industrial psychiatry journal, 19(1), 60-65. https://doi.org/10.4103/0972-6748.77642

[6].Barrett D.C. (2018). Understanding Project Management: A Practical Guide. Canada: CSP Books. Chaput, L. (2011). Project Design: Strategic Information: A Process Approach. Delhi, India: PUQ.

[7].Chen, G. (2017). Project Planning \& Design (PPD) ARE 5.0 Mock Exam (Architect Registration Examination). California: ArchiteG.

[8].Coles E.J\& Barritt C.M.H. (2014). Planning and Monitoring Design Work. New York: Routledge

[9].Dionne, R. (2018). Project Planning for the Stage: Tools and Techniques for Managing Extraordinary Performances. SIU Press.

[10]. Elise, P., O'Brien, B., Laura, N., Glen, B., Maria, A. (2016). Design: Selection of Data Collection Methods. Journal of Graduate in Medical Education, 8 (2): 263-264. https://doi.org/10.4300/JGME-D-16- 00098.1

[11]. Fageha, M. K\& Aibinu, A. A. (2013). Managing Project Scope Definition to Improve Stakeholders' Participation and Enhance Project Outcome. Journal of Social and Behavioral Sciences, 74 (2013) 154 - 164. https://doi:10.1016/j.sbspro.2013.03.038

[12]. Freeman, R. (2007). Managing For Stakeholders: Essential Readings in Ethical Leadership and Management.

[13]. Amherst NY: Prometheus Books.

[14]. Freeman, R. E. (2010). Strategic Management: A Stakeholder approach. US: Cambridge

[15]. Ganesh, K., Sanjey M., Anbudayasankar S.P\& Sivakumar P. (2016). Enterprise Resource Planning Fundamentals of Design and Implementation. New Delhi: Springer. 
[16]. Gasik, S. (2016). National public projects implementation systems: How to improve public projects delivery from the country level. Journal of Social and Behavioral Sciences, 226 (8), 351-357.

[17]. Guillermo, F., Miguel, A., Manuel, V., Sebastian, G., Rodrigo, T., Jorge, S. (2020). Conceptual Framework for the Strategic Management: A Literature Review Descriptive. Journal of Engineering, 2020 (3), 21-34. https://doi.org/10.1155/2020/6253013

[18]. Herder, P\& Wijnia, Y. (2012). A systems view on infrastructure asset management; In: Asset Management; The state of the art in Europe from a life cycle perspective; van der Lei, T., P. Herder, Y. Wijnia (Editors); Springer; ISBN 978-94-007-2723-6

[19]. Hirschman, A.O. (2015). Development Projects Observed. Washington D.C.: Booking Institutions.

[20]. Igwe N.N\& Ude A. O. (2018). Project planning and Implementation in Nigeria: Revisiting International best practices. European Scientific Journal, 14 (3), 152-174).

[21]. Kanyago G.M\& Shukla J. (2017). Role of Project Management Skills on performance of construction projects: A case of selected construction firms in Kigali Rwanda. European Journal of Business and Social Sciences, 6 (7), 1221.

[22]. Klein, H. (2018). Basic Professional Project Planning New Delhi: Springer.

[23]. Le Blanc, P.M., González, V\& Wang, H. (2020). Charismatic Leadership and Work Team Innovative Behavior: the Role of Team Task Interdependence and Team Potency. Journal of Business Psychology. https://doi.org/10.1007/s10869-019-09663-6

[24]. Levitt, G. (2013). Team Planning for Project Managers and Business Analysts. Boca Raton, USA: CRS Press.

[25]. Locatelli, G., Invernizzi, D. C\& Brookes, N. J. (2017). Project characteristics and performance in Europe: An empirical analysis for large transport infrastructure projects. Transportation research part A: policy and practice, 98, 108-122.

[26]. Mainardes, E. W., Alves, H., Raposo, M. (2011). Stakeholder theory: Issues to resolve. Management Decision Journal, 49(2), 226-252. https://doi:10.1108/00251741111109133

[27]. Martinelli, R.J\& Milosevic D.Z. (2016). Project Management ToolBox: Tools and Techniques for the Practicing Project $2^{\text {nd }}$ ed. New Jersey: John Willey \& Sons.

[28]. Melton, T. (2011). Real project planning: developing a project delivery strategy. UK: Butterworth-Heinemann. Moustafaev, J. (2014). Project scope management: A practical guide to requirements for engineering, product, construction, IT and enterprise projects. Boca Raton, USA: CRC Press.

[29]. Msoroka, M. (2012). Project Design and Management Knowledge and Project Management Skills. GRIN Verlag. Naeem, S., Khanzada, B., Mubashir, T \& Sohail, H. (2018). Impact of Project Planning on Project Success with Mediating Role of Risk Management and Moderating Role of Organizational Culture. International Journal of Business and Social Science, 9(1), 88-98.

[30]. Ong'aro, W. O \& Asumptah, K. (2017). Determinants of Succesful Implimentation of Housing Projects in Rwanda: A Case of Roko Construction Company. International Journal of Entrepreneurship and Project Management, 2(2), 69-85.

[31]. Peppard, J\& Ward, J. (2016). The strategic management of information systems: Building a

[32]. Pheng, L.S. (2018). Project Management for the Built Environment: Study Notes Singapore: Springer.

[33]. Pica M. (2015). Project Life Cycle Economics: Cost Estimation, Management and Effectiveness in Construction Projects. NY: Routledge.

[34]. PMI (2013) A Guide to the Project Management Body of Knowledge (PMBOK) $5^{\text {th }}$ ed.. Newton Square. USA: Project Management Institute.

[35]. Remon, F. A \& Sherif, M. H. (2013). Applying lean thinking in construction and performance improvement.

[36]. Alexandria Engineering Journal,52 (4), 679-695. https://doi.org/10.1016/j.aej.2013.04.008

[37]. Roovers, G.J\& van Buuren, M.W. (2016). Stakeholder participation in long term planning of water infrastructure.

[38]. Infrastructure Complexity Journal, 3 (1), 11-18. https://doi.org/10.1186/s40551-016-0013-3

[39]. Serrador, P. (2013). The Impact of Planning on Project Success-A Literature Review. The Journal of Modern Project Management, 1(2), 112-121.

[40]. Sokowski, D. (2015). Mastering Project Management Integration and Scope: A Framework for Strategizing and Defining Project Objectives and Deliverables. FT Press.

[41]. Usadolo, S. E\& Caldwel, M. (2016). A Stakeholder Approach to Community Participation in a Rural Development Project. SAGE open Journal. https://doi.org/10.1177/2158244016638132

[42]. van Buuren, M.W., Driessen, P.P.J., van Rijswick, H.J.F.M \& Teisman, G.R. (2014). Towards legitimate governance strategies for climate adaptation. Combining insights from legal, planning and democratic perspectives. Journal of Regional Environmental Change, 14(3):1021-1033

[43]. Vries, M.S., Juraj N\& David S. (2019). Performance-Based Budgeting in the Public Sector. Switzerland: Palgrave Macmillan.

[44]. Wernerfelt, B. (1984). A resource-based view of the firm. Strategic management journal, 5(2), 171-180. Zandhuis A., Paul S \& Thomas W. (2017). A Pocket Companion to PMI's PMBOK Guide Fifth edition (3 ${ }^{\text {rd }}$ ed.).

[45]. Netherlands: Van Haren Publishing.

[46]. Zwikael, O \& Meredith, J. (2019). Evaluating the Success of a Project and the Performance of Its Leaders in IEEE Transactions on Engineering Management,Journal of management review, $47 \quad(3), \quad 127-134$ https://doi:10.1109/TEM.2019.2925057 